\title{
Data Model for Evaluation of Audience Feedback in Lectures
}

\author{
Hawraa Al Abedi, Ahmad Koubeissi \\ Department of Graduate Studies - Computer and Communications \\ Islamic University of Lebanon \\ Werdanyeh, Mount Lebanon \\ Lebanon
}

Received: October 20, 2020. Revised: December 3, 2020. Accepted: December 7, 2020.

Published: December 10, 2020.

\begin{abstract}
In this article, we discuss the importance of interactivity during lectures and means to evaluate the feedback of the audience. We conduct a literature review on the subject and propose accordingly, a data model for the evaluation of audience feedback in lectures at microscopic and macroscopic levels. We propose a detailed scenario and examine how we are able to simulate such a scenario using the designated data model.
\end{abstract}

Key-Words: - Data Modeling, Evaluation of Audience Feedback, Microscopic Modeling, Macroscopic Modeling, Real-time Feedback in Lectures.

\section{INTRODUCTION}

The moment a lecturer steps into the classroom environment and begins a lecture session, he is overwhelmed by many questions: Do the audience understand the lecture? Are concepts clearly defined for perfect understanding? Is the lecture transferable?

All of these questions are answered via audience feedback. If the lecture is clearly understood, the audience tend to participate and interact with a sense of belonging to the lecture. The positive feedback of the majority paves the way for the lecturer to continue lecturing. However, given the diversity of the audience, the level of understanding tends to change because some will be fast learners while others might be slow or moderate on a certain topic, and will refrain from expressing their concerns due to certain reasons such as shyness [13].

Real-time feedback is an important aspect of the learning environment because it helps lecturers to be more responsive to the audience during a lecture. A clearer idea of audience understanding is captured in a timely manner, thus improving their participation and interaction $[1,4]$. Studies in the literature suggest that analyzing the audience feedback manually requires time and effort [5]. Moreover, there is no given standard on how to perform a quantitative evaluation of the audience feedback.

The main objective of this article is to develop a data model that can be used to assess quantitatively how concepts are being understood in class during a lecture or a presentation. Indicators at both levels, macroscopic (per presentation) and microscopic (per slide), will be used to collect audience feedback while data fusion techniques will be implemented to build observations. The resulting data model can be used by programmers to build high-level language applications for interactive real-time feedback during lectures.

\section{LITERATURE REVIEW}

Defining the term "feedback" in lectures can be stated as information gathered collectively regarding a teaching practice that includes responses, comments and corrections conducted by lecturer in a classroom. Measuring audience feedback is critical for the lecturer since it suggests a qualitative measurement of the effectiveness of his teaching methodology [6]. While several techniques for collection of audience feedback do exist in literature, there is no unified model available that can indicate how to measure numerically the audience feedback in lectures. Hence, in our literature review, we discuss existing tools for collection of audience feedback. This would help us assess the feasibility of integrating our proposed model with several used tools.

A real-time feedback mechanism supported by technology has been developed by authors of [2] using Augmented Reality (AR). This would allow both, 
students and instructors, to measure level of understanding in teaching environment. While audience use their mobile devices to provide feedback, the lecturer wears AR glasses and interacts with Microsoft Kinect tool to visualize how students understand the material. This technology is only efficient for low population audience.

Authors of [3] proposed an interactive lecture using Clickers technology. It enables the lecturer to get realtime feedback from his audience by posing questions and collecting the response from audience who carry radio frequency devices that send signals to a dedicated receiver in the lecture hall. The receiver forwards the responses to a special program that registers audience answers, thus allowing the lecturer to evaluate whether the concepts have been understood during the presentation.

Authors of [4] suggest developing a real-time feedback mechanism for university students using tablets distributed during lectures. Students can interact with their instructor by software on tablet without disturbing their colleagues or issuing their concerns vocally loud. The instructor is able to visualize the students' feedback and interact accordingly.

A student response system, in which subject related questions are asked, is used by authors of [7]. Students are able to discuss possible answers with their classmates and answer individually using handheld remote control units. Similarly, an interactive response system using whiteboards technology has been introduced by authors of [11] to enhance learning in schools by amplifying interactivity in classroom. Results demonstrate enhanced learning outcome with higher levels of satisfaction.

A smart classroom environment is proposed by authors of [8]. The lecture hall is equipped with sensors and monitoring devices that can provide insights about audience activity using sound intensity and movement existence. This activity can be further analyzed to deduce the overall feedback of the audience during the lecture. On the other side, authors of [12] propose a Near Field Communications (NFC)-based interactive learning platform. Students are provided with tags of different difficulty levels to achieve the effect of gradual learning and improve real-time interactivity.

A real-time online classroom response system is proposed by authors of [8] to investigate the feedback of students in lectures. The instructor has to prepare subject-related surveys in advance and present them to students during the lecture. Though the application received good feedback from students, it was rather time-consuming. Similarly, authors of [10] used a classroom response system to assess students' feedback using quantitative and qualitative data. Results showed that the classroom response system can improve interactivity, but again this solution is timeconsuming to the instructor.

\section{PROPOSED DATA MODEL}

Throughout this section, we present our main contribution which is a data model for the evaluation of audience feedback in lectures. We start by discussing the business constraints for the data model. After that, we provide a physical data model (PDM) that shows business constraints as tables, fields of tables, primary key constraints, and foreign key constraints. Next, we implement the depicted physical data model as a database using data definition language (DDL) of structured query language (SQL). Finally, we provide a set of stored procedures that will be used to form an abstraction layer between our developed model and any high-level language application that could be implemented to interface with the model.

\section{A. Business Constraints of the Data Model}

The data model is divided into 2 major parts: one that manages users of the model and other that manages the evaluation of audience feedback in lectures. Regarding the first part, we start by defining the roles of users in the model. They can be administrators, lecturers or audience. Each user should admit a single role and must own credentials in the form of user id and password. Personal information of users includes name, nationality and contact details. We keep track of login history of each user to the model by specifying the host address, login data and time per each login activity.

Regarding the second part of the model which deals with the evaluation of audience feedback, we start by defining presentations of lecturers. We keep track of location, post date, time and number of slides of each presentation. Next, we define possible elements of each slide. Those can be text, figures, charts, animations or anything else. Each element has a coefficient which indicates its significance in a presentation slide. A micro-evaluation of an audience individual is simply a quality grade, from 1 (bad) to 5 (excellent), given for a single element of a slide.

Next we define overall presentation skills of lecturer including talking, eye contact, time management, interaction with the audience, debate skills, clarity of answers, and understanding of the topic. A macroevaluation of an audience individual is simply a quality grade, from 1 (bad) to 5 (excellent), given for a single presentation skill of lecturer. Hence, we note that a micro-evaluation is associated with elements of each 
slide whereas a macro-evaluation is associated with the presentation skills of the lecturer.

The micro-evaluation result (MIC) of single audience individual for a specific presentation is calculated according to the following equation:

$$
M I C=\frac{\sum(\text { element coef } f \times \text { element quality })}{\sum \text { element coeff } .}
$$

The macro-evaluation result (MAC) of single audience individual for a specific lecturer presentation is calculated according to the following equation:

$$
M A C=\frac{\sum(\text { skill coeff } . \times \text { skill quality })}{\sum \text { skill coeff } .}
$$

This means that the values of $M I C$ and $M A C$ will range between 1 (bad) and 5 (excellent). Finally, the micro-evaluation result of all audience for a specific presentation is simply the average $\boldsymbol{M I C}$ computed per each audience individual and is denoted by $\boldsymbol{A V G}-\boldsymbol{M I C}$. Similarly, the macro-evaluation result of all audience is the average $\boldsymbol{M A C}$ computed per each audience individual and is denoted by $\boldsymbol{A V G - M A C}$.

\section{B. Physical Data Model}

Based on the business constraints of the model presented in the previous sub-section, we realize a physical data model that shows 12 tables representing data entities of business constraints. The fields of each table are the attributes of depicted entities. Constraints of tables are of 2 types: primary key constraints that represent non-duplicate fields of tables and foreign key constraints that represent relationships among tables such that a foreign key field in a foreign key table cannot have but one of the values of the primary key field in the primary key table. Figure 1 shows the physical data model in accordance with the described business constraints.

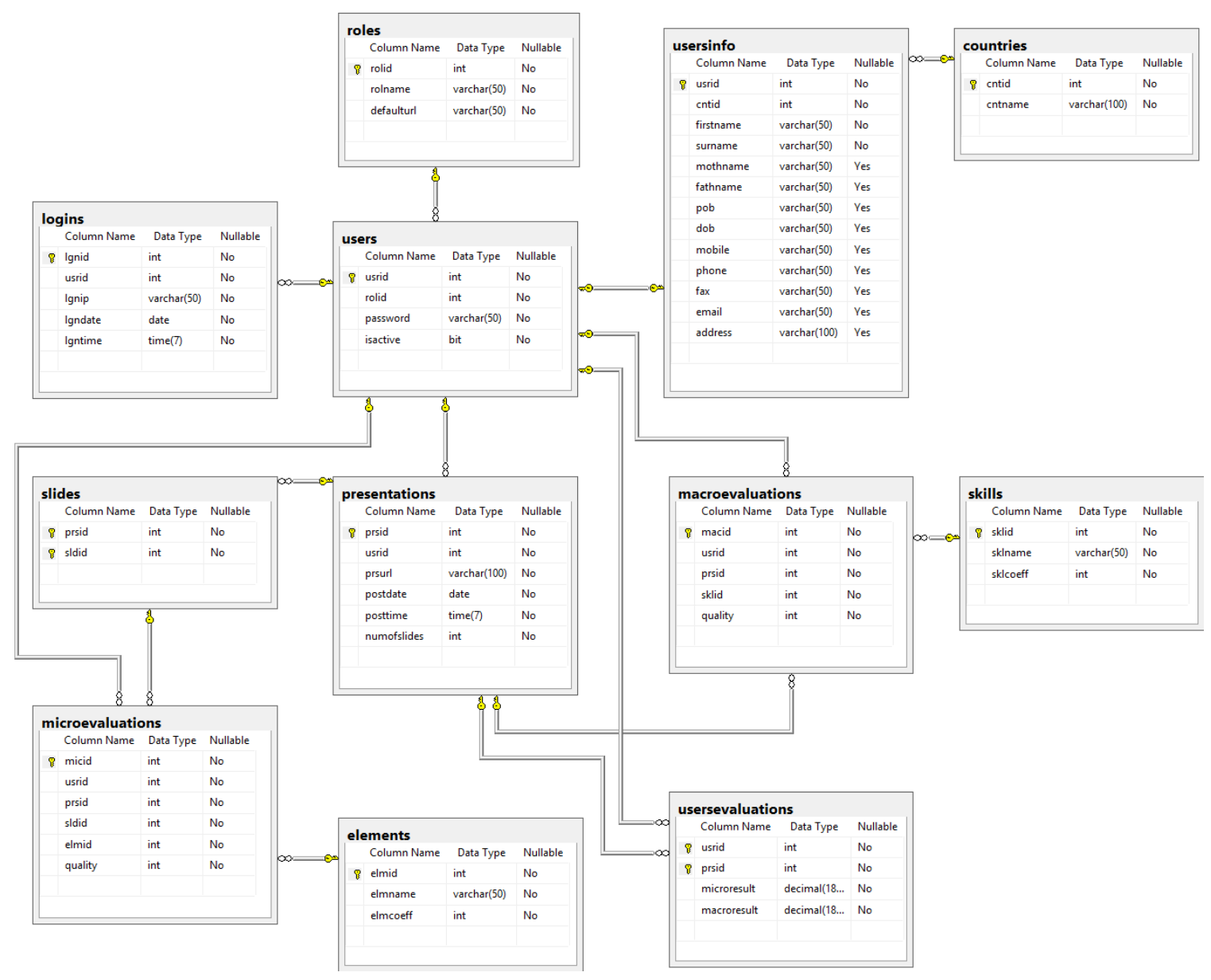

Fig. 1 - Physical Data Model. 


\section{Data Definition Language}

Now to implement the physical data model of the previous section, we need to write some piece of code on the computer. Here, it is obvious that we will implement our model as a database on a database management system. To do that, we need to write data definition language of structured query language to be able to create tables and alter constraints in the created tables.

\section{Stored Procedures for Abstraction of Data Model}

At this point, we have the data model implemented as a database on a database management system. Now, we need to make sure that we have an abstraction layer for our data model such that users may only access the model using this abstraction layer. This would reduce the complexity of the model by hiding all implementation details (tables and constraints) from unauthorized users and enhance the security by providing supervised access to the model. Our abstraction layer will be composed of a set of procedures that are defined and stored as database objects. Users can call these procedures that are parameterized to execute different actions on the model.

For each table in the model, we associate five basic procedures to be able to insert new records, update existing records, delete existing records and select some or all records in a table. Furthermore, two important procedures are defined to calculate the values of micro-evaluation and macro-evaluation results according to what has been defined in business constraints of the model.

Figure 2 shows the flowchart of setmicroresult procedure used to calculate the micro-evaluation result of a single audience individual.

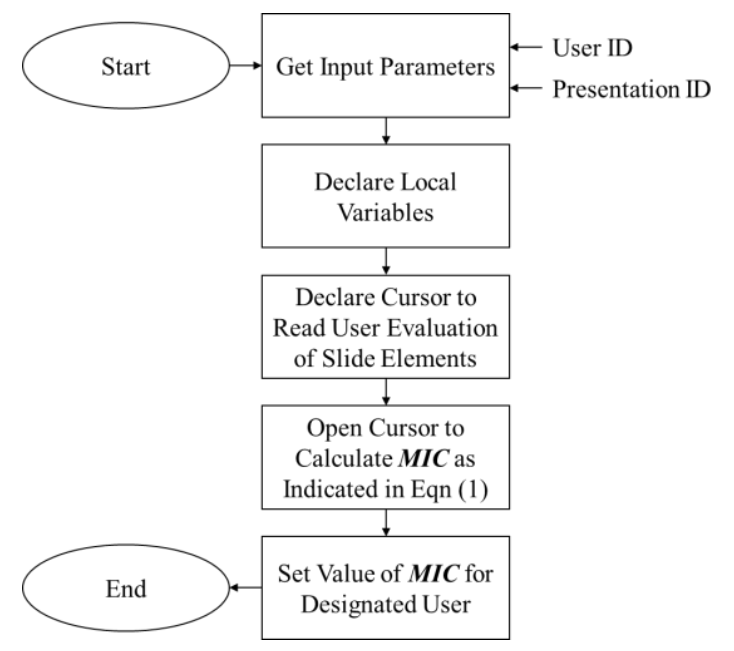

Fig. 2 - Flowchart of setmicroresult Procedure.
Note that for the above procedure, a cursor is being used to be able to determine the sum of the coefficient of elements of slides. The cursors are being deallocated just after being used to release reserved space in memory.

\section{CASE STUDY}

Throughout this section, we present a detailed case study showing a scenario where a lecturer is presenting in front of the audience. We demonstrate how our model can be used to perform the evaluation of audience feedback. We start by presenting a detailed scenario, then we proceed by calling designated stored procedures to simulate the given scenario. Finally, we conclude by remarks on how the model can be best used by another high-level application.

\section{A. Scenario}

A lecturer is presenting a presentation in front of the audience composed of 3 individuals. The lecturer is of Lebanese nationality. His name is Fouad Hussein. Fouad is associated with user ID '1001'. The default password for all designated users in the model is 'abcd'. The audience individuals attending Fouad's presentation are listed in the below table:

Table 1 Users for Audience Individuals.

\begin{tabular}{|c|c|c|}
\hline User ID & Name & Nationality \\
\hline 2001 & Ahmad Farid & Lebanese \\
\hline 2002 & Rami Obeid & Lebanese \\
\hline 2003 & Elie Asmar & American \\
\hline
\end{tabular}

Fouad's presentation is composed of 4 slides. Figures 3, 4, 5 and 6 show each slide of Fouad's presentation respectively. We highlight on the same figures, elements included in each slide so we can interpret them easier in the next section. Recall that according to our model, we will be using elements of slides for micro-evaluations. 


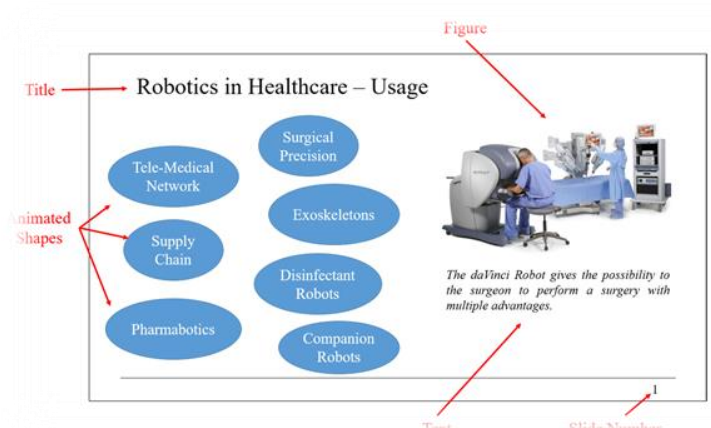

Fig. 3 - First Slide of Presentation.

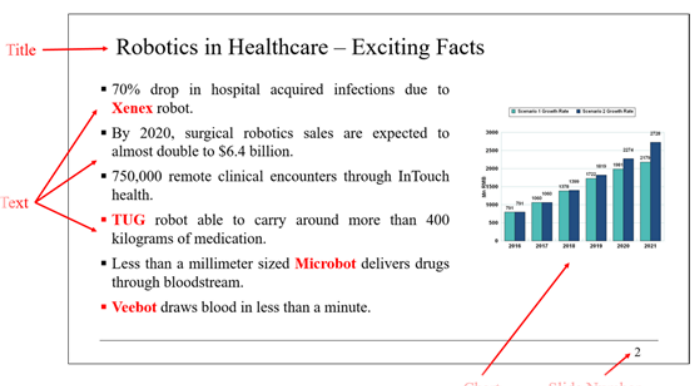

Fig. 4 - First Slide of Presentation.

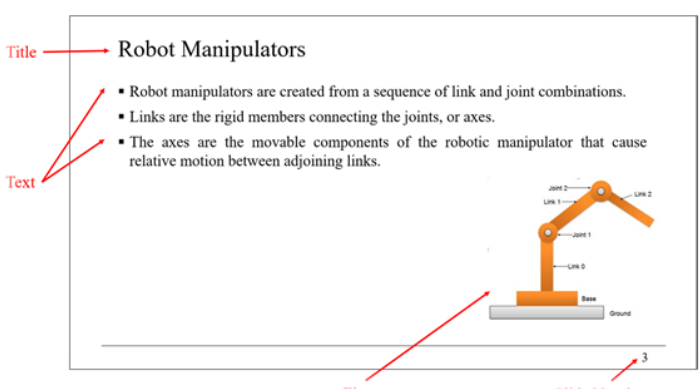

Fig. 5 - Third Slide of Presentation.

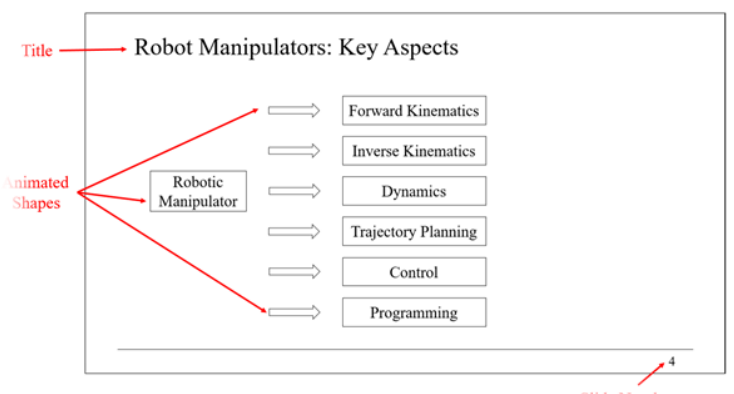

Fig. 6 - Fourth Slide of Presentation.

As we can see from the above figures, the following element types have been used in the slides of the presentation: title, slide number, text, figure, chart, and animated shapes. A coefficient must be allocated to each element type indicating its general relevance, not quality, in slides of the presentation. Note that the coefficients of slide elements can be agreed on by the committee, for example, and set by the administrator. In our case, we suggest coefficients of slide elements in the following table, to be used later for micro-evaluations:

Table 2 Element Types of Slides.

\begin{tabular}{|c|c|c|}
\hline Element ID & Element Type & Coefficient \\
\hline 1 & Title & 3 \\
\hline 2 & Slide Number & 2 \\
\hline 3 & Text & 4 \\
\hline 4 & Figure & 5 \\
\hline 5 & Chart & 5 \\
\hline 6 & $\begin{array}{c}\text { Animated } \\
\text { Shapes }\end{array}$ & 5 \\
\hline
\end{tabular}

Next, we need to define presentation skills types. These skills types will be used for macro-evaluation of the lecturer's overall presentation. Plus, we need to allocate coefficients for skills types indicating their general relevance, not quality. Again, presentation skills types and their corresponding coefficients can be determined by the committee and set by the administrator. We suggest skills types and their corresponding coefficients in the following table:

Table 3 Presentation Skills Types.

\begin{tabular}{|c|c|c|}
\hline $\begin{array}{c}\text { Skill } \\
\text { ID }\end{array}$ & Skill Type & Coeff. \\
\hline 1 & Logical Organization & 3 \\
\hline 2 & Overall Content & 3 \\
\hline 3 & Language Proficiency & 3 \\
\hline 4 & Eye Contact with Audience & 2 \\
\hline 5 & Did Not Read Presentation & 2 \\
\hline
\end{tabular}




\begin{tabular}{|c|c|c|}
\hline 6 & $\begin{array}{c}\text { Talking (Slow, Load and } \\
\text { Clear) }\end{array}$ & 2 \\
\hline 7 & Finish on Time & 2 \\
\hline 8 & Interaction with Audience & 3 \\
\hline 9 & Debate Skills & 4 \\
\hline 10 & Understanding of Topic & 4 \\
\hline
\end{tabular}

Now, each audience individual has to perform a micro-evaluation by providing a quality indicator for each element type in slides of the presentation. We assume the micro-evaluation of each audience individual in a separate table below:

Table 4 Micro-evaluation of First Audience Individual (User ID = 2001)

\begin{tabular}{|c|c|c|}
\hline $\begin{array}{c}\text { Slide } \\
\text { Number }\end{array}$ & Element ID & Quality \\
\hline 1 & 1 (Title) & 4 \\
\hline 1 & 2 (Slide Number) & 5 \\
\hline 1 & 3 (Text) & 4 \\
\hline 1 & 4 (Figure) & 2 \\
\hline 1 & $\begin{array}{l}6 \text { (Animated } \\
\text { Shapes) }\end{array}$ & 5 \\
\hline 2 & 1 (Title) & 3 \\
\hline 2 & 2 (Slide Number) & 5 \\
\hline 2 & 3 (Text) & 5 \\
\hline 2 & 5 (Chart) & 2 \\
\hline 3 & 1 (Title) & 3 \\
\hline 3 & 2 (Slide Number) & 5 \\
\hline 3 & 3 (Text) & 4 \\
\hline 3 & 4 (Figure) & 5 \\
\hline 4 & 1 (Title) & 4 \\
\hline
\end{tabular}

\begin{tabular}{|c|c|c|}
\hline 4 & 2 (Slide Number) & 5 \\
\hline 4 & $\begin{array}{c}6 \text { (Animated } \\
\text { Shapes) }\end{array}$ & 3 \\
\hline
\end{tabular}

Table 5 Micro-evaluation of Second Audience Individual (User ID = 2002).

\begin{tabular}{|c|c|c|}
\hline $\begin{array}{c}\text { Slide } \\
\text { Number }\end{array}$ & Element ID & Quality \\
\hline 1 & 1 (Title) & 4 \\
\hline 1 & 2 (Slide Number) & 5 \\
\hline 1 & 3 (Text) & 4 \\
\hline 1 & 4 (Figure) & 4 \\
\hline 1 & $\begin{array}{c}6 \text { (Animated } \\
\text { Shapes) }\end{array}$ & 5 \\
\hline 2 & 1 (Title) & 5 \\
\hline 2 & 2 (Slide Number) & 5 \\
\hline 2 & 3 (Text) & 4 \\
\hline 2 & 5 (Chart) & 4 \\
\hline 3 & 1 (Title) & 4 \\
\hline 3 & 2 (Slide Number) & 5 \\
\hline 3 & 3 (Text) & 4 \\
\hline 3 & 4 (Figure) & 3 \\
\hline 4 & 1 (Title) & 5 \\
\hline 4 & 2 (Slide Number) & 5 \\
\hline 4 & $\begin{array}{c}6 \text { (Animated } \\
\text { Shapes) }\end{array}$ & 4 \\
\hline
\end{tabular}

Table 6 Micro-evaluation of Third Audience Individual (User ID = 2003).

\begin{tabular}{|c|c|c|}
\hline $\begin{array}{c}\text { Slide } \\
\text { Number }\end{array}$ & Element ID & Quality \\
\hline 1 & 1 (Title) & 3 \\
\hline
\end{tabular}




\begin{tabular}{|c|c|c|}
\hline 1 & $\begin{array}{c}2 \text { (Slide } \\
\text { Number) }\end{array}$ & 5 \\
\hline 1 & 3 (Text) & 3 \\
\hline 1 & 4 (Figure) & 4 \\
\hline 1 & $\begin{array}{c}6 \text { (Animated } \\
\text { Shapes) }\end{array}$ & 3 \\
\hline 2 & 1 (Title) & 4 \\
\hline 2 & $\begin{array}{l}2 \text { (Slide } \\
\text { Number) }\end{array}$ & 5 \\
\hline 2 & 3 (Text) & 4 \\
\hline 2 & 5 (Chart) & 2 \\
\hline 3 & 1 (Title) & 3 \\
\hline 3 & $\begin{array}{c}2 \text { (Slide } \\
\text { Number) }\end{array}$ & 5 \\
\hline 3 & 3 (Text) & 4 \\
\hline 3 & 4 (Figure) & 3 \\
\hline 4 & 1 (Title) & 3 \\
\hline 4 & $\begin{array}{l}2 \text { (Slide } \\
\text { Number) }\end{array}$ & 5 \\
\hline 4 & $\begin{array}{l}6 \text { (Animated } \\
\text { Shapes) }\end{array}$ & 3 \\
\hline
\end{tabular}

Finally, each audience individual has to perform a macro-evaluation by providing a quality indicator for each skill type defined for overall presentation skills. We assume the macro-evaluation of each audience individual in a separate table below:

Table 7 Macro-evaluation of First Audience Individual (User ID = 2001).

\begin{tabular}{|c|c|}
\hline Skill ID & Quality \\
\hline 1 (Logical Organization) & 4 \\
\hline 2 (Overall Content) & 3 \\
\hline 3 (Language Proficiency) & 5 \\
\hline
\end{tabular}

\begin{tabular}{|c|c|}
\hline $\begin{array}{c}4 \text { (Eye Contact with } \\
\text { Audience) }\end{array}$ & 3 \\
\hline $\begin{array}{c}5 \text { (Did Not Read } \\
\text { Presentation) }\end{array}$ & 3 \\
\hline 6 (Talking) & 4 \\
\hline 7 (Finish on Time) & 3 \\
\hline $\begin{array}{c}8 \text { (Interaction with } \\
\text { Audience) }\end{array}$ & 4 \\
\hline 9 (Debate Skills) & 4 \\
\hline 10 (Understanding of Topic) & 3 \\
\hline
\end{tabular}

Table 8 Macro-evaluation of Second Audience Individual (User ID = 2002).

\begin{tabular}{|c|c|}
\hline Skill ID & Quality \\
\hline 1 (Logical Organization) & 4 \\
\hline 2 (Overall Content) & 4 \\
\hline 3 (Language Proficiency) & 5 \\
\hline $\begin{array}{c}4 \text { (Eye Contact with } \\
\text { Audience) }\end{array}$ & 4 \\
\hline $\begin{array}{l}5 \text { (Did Not Read } \\
\text { Presentation) }\end{array}$ & 4 \\
\hline 6 (Talking) & 5 \\
\hline 7 (Finish on Time) & 3 \\
\hline $\begin{array}{c}8 \text { (Interaction with } \\
\text { Audience) }\end{array}$ & 4 \\
\hline 9 (Debate Skills) & 5 \\
\hline 10 (Understanding of Topic) & 4 \\
\hline
\end{tabular}

Table 9 Macro-evaluation of Third Audience Individual (User ID = 2003).

\begin{tabular}{|c|c|}
\hline Skill ID & Quality \\
\hline 1 (Logical Organization) & 4 \\
\hline
\end{tabular}




\begin{tabular}{|c|c|}
\hline 2 (Overall Content) & 5 \\
\hline 3 (Language Proficiency) & 4 \\
\hline $\begin{array}{c}\text { (Eye Contact with } \\
\text { Audience) }\end{array}$ & 4 \\
\hline $\begin{array}{c}\text { (Did Not Read } \\
\text { Presentation) }\end{array}$ & 4 \\
\hline 6 (Talking) & 4 \\
\hline 7 (Finish on Time) & 4 \\
\hline 8 (Interaction with Audience) & 4 \\
\hline 9 (Debate Skills) & 4 \\
\hline 10 Understanding of Topic) & \\
\hline
\end{tabular}

\section{B. Simulation of Presented Scenario using Our Model}

In this sub-section, we demonstrate how to simulate the scenario previously defined. We present a list of calls to the implemented stored procedures in our model. Recall that the call for procedures is supposed to happen within the high-level application to be developed for evaluation of audience feedback in lecture. We start by the management of users in the model.

First, we add their designated countries (nationalities) and roles (lecturer or audience), then we add lecturer user and audience individuals' users together with their credentials as indicated in table 1. After that, we define elements of presentation slides as indicated in table 2 and presentation skills types as defined in table 3 . Then we add presentation of the lecturer to the model and its related four slides. Next, we add micro-evaluations of each audience individual as indicated in tables 4,5 and 6 respectively. Finally, we add macro-evaluations of each audience individual as indicated in tables 7, 8 and 9 respectively. The flowchart for creation and simulation of the scenario defined is shown in figure 7.

Now to simulate the defined scenario in the model, we start by calculating the micro-evaluation result and macroevaluation result for each audience individual as defined. This can be done by executing the setmicroresult and setmacroresult procedures respectively. Finally, to get the average microevaluation and macro-evaluation results, we execute the procedures getavgmicroresult and getavgmacroresult respectively.

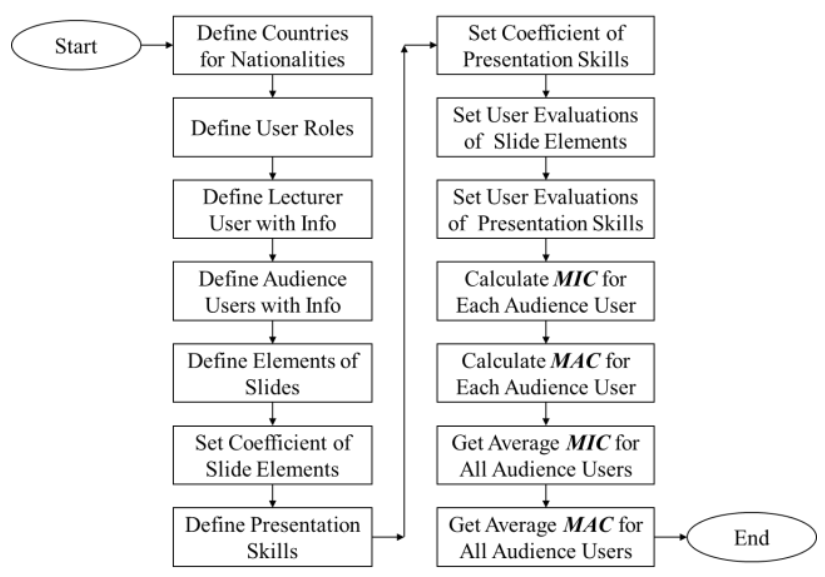

Fig. 7 - Flowchart for Creation and Simulation of Defined Scenario.

\section{Notes on Using the Model}

Recall that we implemented our model as a database on a database management system (Microsoft SQL Server). To benefit from the model in a real-life situation, we further need to develop a high-level language application that hides all complexities of stored procedures calls from ordinary users, in our case audience individuals and judging committee. The application itself is beyond the scope of this research. Nevertheless, anybody who is interested in developing such an application must take into consideration the following notes:

a) There should be a registration form for new users.

b) There should be user authentication and authorization procedures at the application level to ensure maximum security upon the usage of the model.

c) Upon uploading of a new presentation by the lecturer, the process of reading slides and elements of slides must be automated.

d) During the presentation of each slide, audience individuals must be able to evaluate elements of slides in real-time to get micro-evaluations.

e) Macro-evaluations must be completed at the end of the presentation, unlike micro-evaluations which should be conducted at each presentation slide.

f) It is up to high-level language application to formulate the overall result based on average micro-evaluation and macro-evaluation results of all audience individuals. 


\section{CONCLUSION}

Interactivity is a very important component of teaching and learning and is considered a key to success in traditional classrooms. Enhancing interaction in the classroom can lead to better and more effective learning. Throughout this article, we discussed the concept of audience feedback in lectures and the importance of having a technique to evaluate it quantitatively. We proposed a model that can be used to manage lecturers' presentations and permits the audience to evaluate it at two levels: microscopic and macroscopic. At the microscopic level, the audience can interact and evaluate elements in presentation slides such as text, animated shapes, graphs, figures, etc. whereas at the macroscopic level, the audience can evaluate overall presentation skills of lecturer such as talking, timing, debate skills, understanding of the topic, etc.

We developed an abstraction layer for the designated model. This layer is composed of tens of stored procedures that can be called from within a high-level application to manage users of the model, lecturer's presentations and audience feedback at both levels, microscopic and macroscopic. We provided a case study showing how we can simulate a given scenario using stored procedures of the model.

We believe that our proposed model is unique in its approach for the evaluation of audience feedback compared to what we have read in literature. As a perspective, we intend to develop three correlated high-level language applications to interact with the model: One for lecturer to be able to upload his presentation and extract all elements from every slide, one for audience and permits each individual to conduct his/her micro and macro-evaluation, and one for committee members who would be able to analyze overall feedback of audience (micro and macro).

\section{References:}

[1] A. AlShahrani, S. Mann, M. Joy, "Immediate Feedback: A New Mechanism for Real-Time Feedback on Classroom Teaching Practice", International Journal on Integrating Technology in Education (IJITE) Vol.6, No.2, June 2017.

[2] T. Zarraonandia, I. Aedo, P. Diaz, A. Montero, "An Augmented Lecture Feedback System to Support Learner and Teacher
Communication", British Journal of Educational Technology, 44(4), 616-628.

[3] J. E. Caldwell, "Clickers in the Large Classroom: Current Research and BestPractice Tips. CBE - Life Sciences Education, 6(1), 9-20, 2007.

[4] A. W. Mogwe, "Real-Time Concept Feedback in Lectures for Botho University Students", (IJACSA) International Journal of Advanced Computer Science and Applications, Vol. 9, No. 6, 2018.

[5] T. Sitzmann, K. Ely, K. Brown, K. Bauer, "Self-Assessment of Knowledge: A cognitive Learning or Affective Measure?", Academy of Management Learning and Education, 9(2), 169-191, 2010.

[6] W. H. Hedgecock, R. M. Rouwenhorst, "Clicking Their Way to Success: Using Student Response Systems as a Tool for Feedback", Journal for Advancement of Marketing Education, Volume 22, Issue 2, 2014.

[7] K. Egelandsdal, R. J. Krumsvik, "Clickers and Formative Feedback at University Lectures", Springer Educ Info Technol, 22, 55-74, 2017.

[8] N. Gligoric, A. Uzelac, S. Krco, "Smart Classroom: Real-Time Feedback on Lecture Quality”, 2012 IEEE International Conference on Pervasive Computing and Communications Workshops, Lugano, 2012, pp. 391-394.

[9] L. Sun, "The Use of a Real Time Online Class Response System to Enhance Classroom Learning”, ASEE Engineering Design Graphics Division $-69^{\text {th }}$ Midyear Conference, Normal, IL, October 12-14, 2014.

[10] K. Siau, H. Sheng, F. F. Nah, "Use of a Classroom Response System to Enhance 
Classroom Interactivity", IEEE Transactions on Education, Vol. 49, No. 3, pp. 398-403, 2006.

[11] H. Chuang, C. Shen, L. Wang, "Using an Interactive Response System in Conjunction with Interactive Whiteboards Technology to Enhance Learning", 2008 Fourth International Conference on Natural Computation, pp. 657661, Jinan, 2008.

[12] W. H. Lee, M. C. Kuo, C. C. Hsu, "An InClassroom Interactive Learning Platform by Near Field Communications", $20158^{\text {th }}$ International Conference on UBI-Media Computing, pp. 360-364, Colombo, 2015.

[13] A. Latham, N. Hill, "Preference for Anonymous Classroom Participation", Journal of Management Education, 38(2), 192-215, 2013.

[14] M. C. Wang, G. D. Heartel, H. J. Walberg, "What Influences Learning? A content Analysis of Review Literature", Journal of Education Research, 84(1), 30-43, 1992.

[15] C. P. Fulford, S. Zhang, "Perceptions of Interaction: The Critical Predictor in Distance Education", American Journal of Education Research, 7(3), 8-21, 1993.

\section{Contribution of individual authors to the creation of the article}

- Hawraa Al Abedi contributed to the design of the data model, implemented it on the database management system, developed the procedures and carried out the simulation.

- Ahmad Koubeissi contributed to the design of the data model and proposed the testing scenario.

\section{Creative Commons Attribution License 4.0} (Attribution 4.0 International, CC BY 4.0)

This article is published under the terms of the Creative Commons Attribution License 4.0

https://creativecommons.org/licenses/by/4.0/deed.en_US 